Résumés des conférences et travaux

\title{
Dialectologie grecque
}

\section{Laurent Dubois}

\section{OpenEdition \\ Journals}

Édition électronique

URL : https://journals.openedition.org/ashp/211

DOI : 10.4000/ashp. 211

ISSN : 1969-6310

Éditeur

Publications de l'École Pratique des Hautes Études

\section{Édition imprimée}

Date de publication : 1 octobre 2008

Pagination : 64-65

ISSN : 0766-0677

\section{Référence électronique}

Laurent Dubois, «Dialectologie grecque », Annuaire de l'École pratique des hautes études (EPHE), Section des sciences historiques et philologiques [En ligne], 139 | 2008, mis en ligne le 09 décembre 2008, consulté le 12 juillet 2021. URL : http://journals.openedition.org/ashp/211 ; DOI : https://doi.org/ 10.4000/ashp.211 


\title{
DIALECTOLOGIE GRECQUE
}

\author{
Directeur d'études : M. Laurent DuboIs
}

Programmme de l'année 2006-2007 : I. Inscriptions grecques archaïques récemment publiées. - II. Commentaire de l'Alexandra de Lycophron (suite).

C'est, comme souvent, le hasard des publications épigraphiques et les travaux personnels des auditeurs qui ont déterminé le choix des inscriptions étudiées au séminaire, cadre approprié à la préparation de leur recension dans le Bulletin épigraphique de la Revue des études grecques.

Nous avons consacré cinq séances à la célèbre inscription des Mystères d'Andanie,

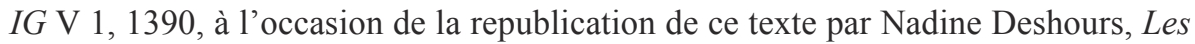
mystères d'Andanie, Ausonius éditions, 2006. Cette inscription qui, avec ses 194 lignes, est la plus longue inscription dialectale connue date des années 91/90 a. C. (la date de $24 p$. C. proposée par Thémélis, $S E G$ 52, 412, qui compte selon l'ère d'Actium et non à partir de 146, est beaucoup moins probable). Ce texte prévoit toutes les dispositions concernant le bon développement des mystères : le choix des organisateurs appelés hiéroi et hiérai, les processions, la vêture des initiés, le financement de la fête, la fourniture des victimes, le statut d'asylie du sanctuaire, l'adduction d'eau pour les cérémonies, etc. Nous avons repris la traduction en quelques endroits dans lesquels l'auteur n'avait pas identifié quelques formes typiquement doriennes : ainsi, 1. 83, dans

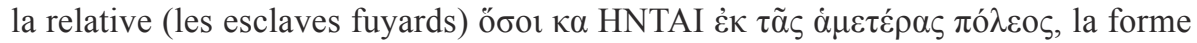
de subjonctif n'a rien à voir avec le verbe ñ $\mu \alpha \iota$ « être assis » : il s'agit de l'équivalent dorien, bien attesté à Delphes, de l'attique $\tilde{\omega} \sigma \mathrm{l}$, et l'on traduira « tous ceux qui sont originaires de notre cité ». Pour le culte d'Apollon Karneios qui figure dans le texte, nous avons attiré l'attention sur le fait qu'une publication récente de Thémélis, Praktika Ath. Arch. Hét., 2001, p. 70-71 (= SEG 52, 412), faisait état de la découverte au centre historique de Messène d'une association de Karneiastai et de hiéroi, ce qui confirme que le sanctuaire d'Andanie devait être une succursale de celui de la métropole messénienne. Les prescriptions vestimentaires concernant la vêture des initiés nous ont amenés à revoir le texte de l'inscription de la cité arcadienne voisine de Lycousoura $I G \mathrm{~V}$ 2, 514, qui, rédigé dans un arcadien tardif, mentionne des interdits assez semblables.

La publication en 2005 d'un recueil d'études consacrées aux Lois de Gortyne, par l'École archéologique italienne d'Athènes, La Grande Iscrizione di Gortina. Centoventi anni dopo la scoperta, E. Greco et M. Lombardo (éd.), nous a incités à partir de l'étude dialectologique d'Albio Cassio dans ce recueil, p. 85-98, pour étudier la colonne $\mathrm{X}$ dans laquelle figurent les indications concernant l'adoption appelée ớv $\pi \alpha v \sigma i \varsigma$, terme institutionnel qui insiste sur la notion de déclaration publique, * àv $\alpha \varphi \alpha v \sigma ı \zeta$. Nous avons particulièrement étudié le passage dans lequel il est question du fait que l'adopté peut être issu de n'importe quelle couche de la société crétoise, ò $\pi \tilde{o} \tau \imath \lambda \lambda \tilde{\varepsilon} 1$ «d'où que l'on veuille»; le relatif comporte une vieille désinence d'ablatif 
indo-européen, celle du delphien Foík $\omega$, et le verbe « vouloir » apparaît ici sous sa forme typiquement dorienne, $\lambda \tilde{\omega}, \lambda \tilde{\eta} v$ issue d'un radical ancien * ${ }^{*} l_{2} H_{1}$, celui de attique $\lambda \tilde{\eta} \mu \alpha$, et du latin velle, avec un autre degré radical.

Nous sommes ensuite allés en mer Égée. D'abord à Chios puisqu'un recueil consacré à la mémoire de W. G. Forrest, intitulé XIAKON $\triangle Y M \Pi O \Sigma I O N$, et publié en 2006 à Athènes par G. Malouchou et A. Matthaiou, fait connaître une certain nombre d'inscriptions nouvelles. Nous nous sommes attachés à l'étude des textes les plus anciens : à la vente d'une prêtrise qui contient la mention des devoirs de la prêtresse, ainsi que les éléments du casuel auquel elle a droit; à une borne de sanctuaire qui porte

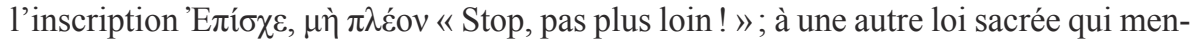

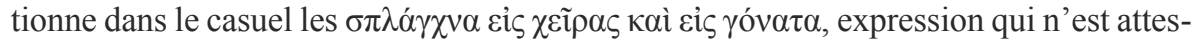
tée que dans l'Est de l'Égée et qui doit faire allusion aux viscères déposés sur les bras et les genoux des statues de divinités assises.

De Théra nous avons étudié une dédicace archaïque à Achille, publiée par Sigalas et Matthaiou, Horos, 2000-2003, p. 259-268, qui constitue en soi un unicum car on sait que le culte de ce héros est quasiment absent du monde dorien. Nous avons émis l'hypothèse qu'il pourrait s'agir d'une influence ionienne, sans exclure que le culte puisse être un vestige d'époque mycénienne.

Enfin nous avons fait une mise au point sur l'alphabet paro-thasien en commentant une nouvelle loi funéraire de Paros de la fin du $\mathrm{VI}^{\mathrm{e}}$ s. $a$. C., publiée elle aussi par A. Matthaiou, ibid., p. 307-310, loi qui stipule l'interdiction d'être enterrés dans un enclos déterminé à ceux qui ne seraient pas des phrètères.

Nous avons terminé l'année par un long détour thessalien à la faveur de la publication de décrets de la basse époque hellénistique encore très dialectaux de Larissa par Br. Helly. Le premier paru dans Chiron, 2006, p. 171-203, le second BCH, 2004-2005, 378-392. Tout en saluant ces publications, nous avons encore une fois déploré la lenteur de la publication des archives thessaliennes par l'équipe lyonnaise du CNRS : les études dialectologiques pour cette région sont ainsi littéralement bloquées. Une mise en ligne du type de celle qui a été initiée pour le corpus de Thespies préparé par le feu Paul Roesch serait un modèle à développer. 